\title{
The Development and Practice of Curriculum Based on Four Educational Ideas
}

\author{
Mingchun Zhang \\ Department of Information Science \\ Beijing City University \\ Beijing, China
}

\author{
Xin Wang \\ Department of Information Science \\ Beijing City University \\ Beijing, China
}

\begin{abstract}
In this study, according to the four educational ideas, the training model of students' growth path has been established. The development of curriculum is conducted through instancing the curriculum of rail transit safety and management. The curriculum objectives are quantified and the comprehensive experiment is provided to train students' operational ability, enabling them to apply what they have learned.
\end{abstract}

Keywords-four educational ideas; growth path model; curriculum development; curriculum objectives

\section{INTRODUCTION}

With the social and economic development, the vocational education separates from the needs of industries and enterprises. Students lack the comprehensive quality and knowledge structure. Curriculum development is a term widely used in the curriculum field. It originates from curriculum development and curriculum construction. All educational institutions inevitably take curriculum development as the important means to adjust the contradiction between education and social demands.

\section{FOUR EDUCATIONAL IDEAS AND ITS MAIN PRINCIPLES}

Beijing City University aims at training students' application ability, proposing the four educational ideas through years of exploration, namely suitable education, holistic education, effective education and practical education. The main core of four educational ideas: adhere to the studentoriented principle, and the setting of curriculum system shall adapt to students' growth and requirements; insist demand orientation, strengthen the matching between talent training and the economic and social development and explore the construction of curriculum module as well as strengthen the training of practice ability; emphasize ability training and educate people through practice, strengthen the development and application of comprehensive or design-based practice projects as well as college students' innovation and entrepreneurship education, supporting students to research, strengthening the construction of education bases by virtue of practice and forming the composite force of practice education; insist the integration of industry and education, promote the deep cooperation between schools and enterprises, and closely combine the school development and major construction with the economic and social development. Meanwhile, optimize curriculum system and implement the training process, conduct quality evaluation and the long-term mechanism that all project platforms are open to talent training, in order to promote the education.

\section{ThE ESTABLISHMENT OF STUdENTS' ABILITY TRAINING MODEL}

The four educational ideas insist the student-oriented principle. The establishment of students' growth model must be analyzed from students' roles.

\section{A. Characteristics of Students}

Students of our school have the following characteristics in learning:

- Some lack learning interest and motivation: Students fail to cognize the professional roles in the future, so it's difficult for them to identify the value of future profession and pay necessary attention to the importance of curriculum. Some students only pursue 60 points and pass the examination through doing a crash job before examination.

- The difference of students is big: In classroom teaching, teachers teach knowledge and students learn knowledge passively. It has failed to meet students' needs. Students are different in understanding knowledge, so some of them cannot understand if the teacher teaches uniformly.

- Students have a strong operation ability

\section{B. The Establishment of Students' Ability Training Model}

From the perspective of student orientation, students' ability to apply practical issues can be trained. Competent students can be guided to solve complex problems; as for the means, research the combination of curriculum and industry, stimulate students' learning interest, determine the curriculum objectives and establish the target knowledge system. Teachers must guide students and students need to practice more and frequently. The details are shown in "Fig. 1". 


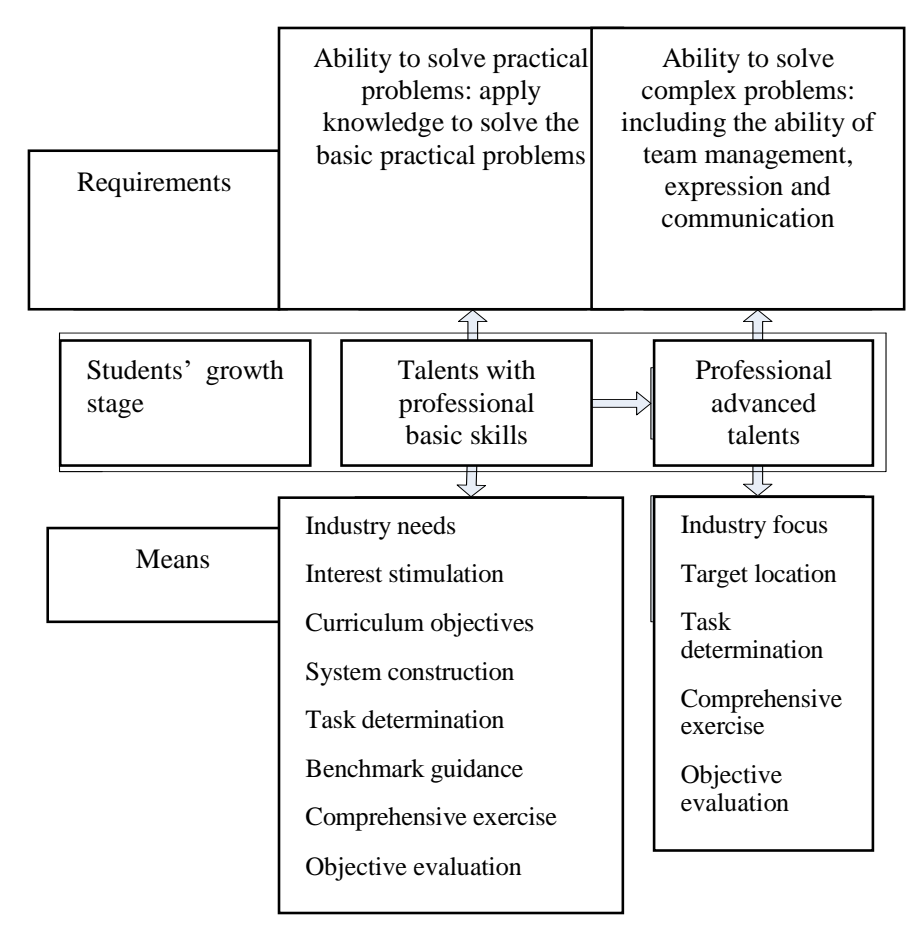

Fig. 1. Model of student's growth training path.

In order to determine the needs of industry and stimulate students' learning interests, the core is to determine the curriculum objectives, establish the knowledge system and determine the tasks:

1) Industry needs:Analyze job requirements and ability for posts and turn things frequently done in job into the cases in classroom.

2) Interest stimulation: For talents with the professional basic skills, the change of roles of teacher and student must be realized: instead of teachers' passive teaching, students learn actively. Here the form of flipped classroom can be used. Besides, we must use application to train students' operation ability [3].

Professional advanced talents shall be guided to think the complicated problems like the research hotspot of the industry, and their interests must be stimulated.

3) Curriculum objectives and tasks: The determination of curriculum objectives and the establishment of knowledge system shall be quantified and accurate, and the tasks are determined according to the objectives. DACUM [4] model is used to develop the task of curriculum. The specific procedure is shown in "Fig.2".

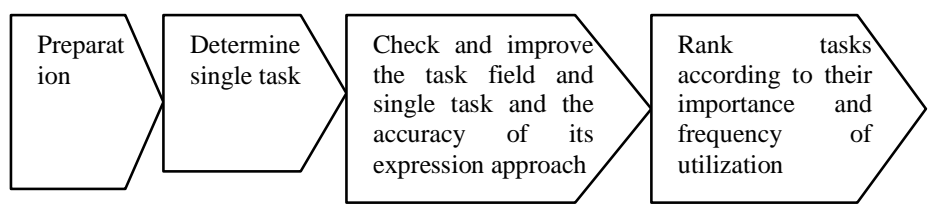

Fig. 2. Flow of DACUM task analysis.
4) Benchmark guidance: It focuses on teachers' teach. Teachers tease the standard, teach the analysis process and method, instance specific cases and establish the benchmark to guide students.

5) Comprehensive practice: Turn knowledge into ability and pay attention to class exercise and homework. The task shall focus on comprehensive or design-based cases. The development of cases mainly bases on the practical problems of posts.

6) Objective evaluation: Change the common evaluation method that checks the knowledge points through closed-book exam in the end of term and clarify each objective. Build the relatively complex problems for objectives and design tasks for problems. Teachers assess the tasks completed by students to check students' ability in knowledge application.

\section{CASE ANALYSIS}

This paper instances curriculum and is student-oriented, quantifying the curriculum objectives and sorting the curriculum system according to the needs of industries and posts. Interest stimulation, benchmark guidance, comprehensive exercise and phased assessment are mentioned.

\section{A. Overall Objective of Curriculum}

Industries and posts require students to grasp the theoretical knowledge of safety management and evaluation, preliminarily analyze the common safety problems in stations and have the ability to solve them and evaluate the safety. They shall use methods and theories to reduce accidents and minimize the secondary disaster of accident happened.

In the future 5 years, students shall focus on the prevention and treatment of accidents. After 5 years, the ability to investigate and evaluate accidents is increasingly important. Therefore, the curriculum shall focus on the prevention and treatment of accidents and the ability to investigate and evaluate accidents.

\section{B. The Establishment of Knowledge System in the Curriculum}

Research the position of curriculum in the curriculum system and establish the knowledge system through ability. The curriculum system is divided into 5 knowledge modules, namely safety sign, accident prevention, accident treatment, accident investigation and safety evaluation, as shown in Fig. 3. 


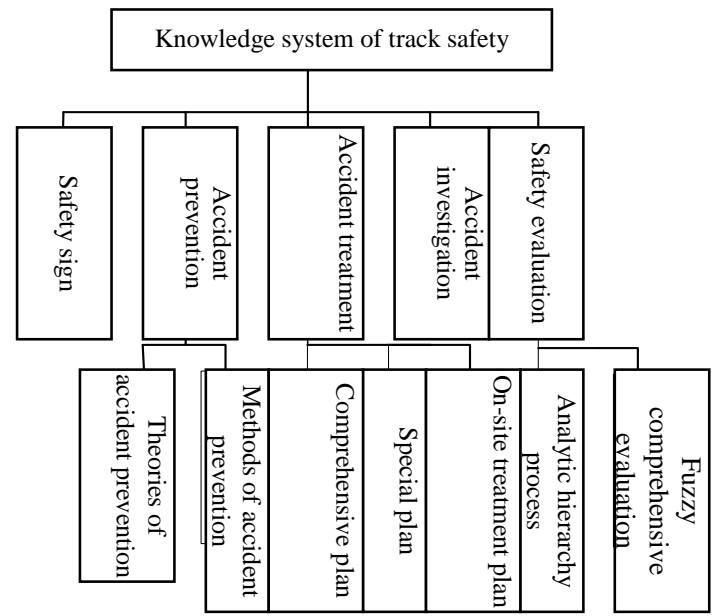

Fig. 3. The establishment of core knowledge system in the curriculum

\section{Determine the Basic Curriculum Objectives}

The description of objectives required by the curriculum system shall be detailed for students to fulfill tasks. Meanwhile, each task shall be assessed. The curriculum has four subtargets according to the overall objective. Tasks are designed according to the target. The objectives of tasks are described as follows:

The principle to design four kinds of safety signs can be clarified through listing the safety signs in daily work of stations, to make students able to modify the wrong signs appearing in stations and design some new signs.

Students can distinguish four kinds (prohibition, warning, instruction and information sign) safety signs and tell the category of common safety signs in stations.

Students can state the design principle of the four kinds of safety signs and find out the error in the wrong signs.

Students can redesign grade post and curve post according to the design principle of safety signs.

The practical problems like the accident of train derailment are instanced to make students able to analyze and prevent accidents through safety worksheet and accident tree, independent design the safety worksheet and accident tree to prevent such accidents as traffic collision.

Students can state the steps and the elements of the safety worksheet and accident tree.

Students can distinguish the objects and characteristics of the two methods and choose the suitable methods to prevent a kind of accident.

Students are familiar with the steps to compile the safety checklist and compile the safety checklist of fire fighting equipment in metro station.

Students know the qualitative and quantitative analysis of accident tree and conduct the qualitative and quantitative analysis of train collision accident through accident tree, find out the unsafe factors and reduce the possibility to happen accidents.

The practical problem of gusty large passenger flow in stations is instanced to make students able to compile on-site emergency plan and treat emergencies and solve practical problems that passengers fall off the platform by accident.

Students state the three emergency plans and its design principles and steps.

According to the practical problems such as passengers fall of the platform accidentally and people is clamped by the safety door, students can find out the unreasonable part of onsite emergency plans in stations and can compile on-site emergency response plan for some kind of accidents.

According to the practical problems such as passengers fall of the platform accidentally and people are clamped by the safety door, students conduct on-site emergency treatment for the accidents and reduce the occurrence of secondary accidents.

The safety of the station is instanced to make students able to evaluate the safety of the station roundly and find out related problems and propose measures to improve.

Students can observe at least three methods of safety evaluation and write the idea and steps of fuzzy comprehensive evaluation from memory.

Students can evaluate the safety status of a station through fuzzy comprehensive evaluation methods and analyze problems related to safety in the station and propose the rectification measures.

\section{Advanced Target}

Further excavate the contents of curriculum and depend on the hot issues of social research to create the complicated projects. Organize the team of excellent students and train them to make them grasp the ability of academic research, writing ability and team-work ability, improve their comprehensive quality. Meanwhile, we can excavate the projects and let students participate in high level discipline competition.

The contents of the curriculum include two parts, first, the design of safety color and safety signs; second, evaluate the safety of stations.

The safety color and safety signs in some metro station of Beijing are researched to make students able to modify the wrong signs appeared in the line and redesign the signs and adjust the position in the form of student team

Students can investigate the signs of some line (prohibition, warning, instruction and information signs) and sort the safety signs.

Students can find out the problem of signs investigated and the further improvement measures and plans according to the design of safety signs and the organization principle of passenger flow. 
Students can conclude the investigation contents and design contents and normatively write down the investigation report of safety signs.

Some metro station in Beijing is researched to make students able to evaluate the safety of stations through more complicated models (like neural network and gray model) in the form of student team.

Students can evaluate the safety status of a specific station through more complicated models (like neural network and gray model), analyze safety problems and propose rectification measures.

Students can normatively write down the research report of safety evaluation and accurately express the projects.

\section{E. Interest Stimulation}

It is realized through flipped classroom. Two changes will be realized to stimulate students' learning interest and enthusiasm:

Students' roles change. Instead of being taught by the teacher, students learn actively. The change of role needs the establishment of tasks. The curriculum tasks are designed according to the curriculum objectives. The tasks include the curriculum can solve what kind of problems and which methods will be used in solving problems.

The curriculum changes from teaching to discussion. In order to fulfill the task, students discuss in class and the teacher guide the discussion to combine the processes in and after class.

\section{F. Benchmark Guidance and Evaluation}

The teaching effect of curriculum and students' gain are realized through this part. Teachers guide and establish the excellent sample to correctly fulfill the task according to students' discussion in the setting of tasks. Other groups can improve and modify the tasks according to the excellent samples.

The evaluation of the curriculum is divided into three phased evaluation and one final examination, with individual or group as the unit. The evaluation contents base the curriculum objectives. In this paper, the second and the third objectives, the accident prevention and accident treatment in the curriculum are instanced and its evaluation contents and requirements are described.

Students conduct the qualitative and quantitative analysis of some kind of accidents in urban rail transit through accident tree, and the key points are as follows:

Students can analyze some accident of urban rail transit and draw the accident tree of the accident;

The number of elementary events is no less than 12 ;

Students conduct the qualitative analysis of the accident tree (minimum cut set and minimum path set);

Students conduct quantitative analysis of the accident tree (analysis of probability and the importance of results, analysis of probability importance and analysis of the criticality importance), and the probability of elementary events can be designed by themselves.

The key points of on-site treatment plan for falling objects in the track area of the platform follows:

Students can compile the on-site treatment plan for the falling objects in the track area of the platform;

The main contents of on-site treatment plan include: the characteristics of accidents, emergency organization and responsibility, emergency disposal, precautions and other. Other includes: the guarantee of emergency supplies and resources, the management requirement of on-site treatment plan, site recovery, supportive attachments such as the layout chart of areas or places;

The basic requirements of on-site treatment plan are as follows: It must be operational. Specific steps and standards of emergency action must be explicit to make emergency personnel effectively and rapidly conduct the emergency work, instead of being at a loss or having wrong actions because the disturbance of emergencies. It must be coordinating. It must consider the connection and collaboration of sectors participating in the emergency action, and no contradictions and logical errors shall exist. It must be pertinent. The concrete implementation contents and steps of emergency action must be described according to the condition of on-site accident, the emergency function and task of emergency subject. It must be continuous. It must consider the change of the organization and personnel participating in the emergency and the continuous process of emergency preparedness, response, rescue and recovery.

\section{CONCLUSION}

Compared with the construction of curriculum development, the curriculum reform based on the four educational ideas is student-oriented, paying attention to the integration with industry and the needs of posts, the quantification of objectives and the setting of students' comprehensive experiment. At the meantime, it provides phased assessment to evaluate each target of students and improves students' ability of turning knowledge into the practical application, providing growth paths for students at different levels, considering students' level and reasonably guiding students' learning.

\section{REFERENCES}

[1] Hao Deyong. Curriculum Development Methods [M]. Education Science Press, 2002

[2] Guo Jiong, Zhu Zhiting. Research on the Methods for Curriculum Development in Vocational Education on the Basis of Role Analysis [J], Chinese Vocational and Technical education, the 3rd Issue in 2011, 3539

[3] Zhang Jinlei. Research on the Teaching Model of Flipped Classroom [J] Journal of Distance Education, 2012, 4

[4] Shi Weiping. Technology for Curriculum Development in Vocational Education [M], Shanghai: Shanghai Educational Publishing House, 2006, 98 